\title{
The Relationship between HRM Strategies and Sustainable Competitive Advantage: Strategic Agility as a Mediating Variable
}

\author{
Maged Barahma ${ }^{1,}$, Mohmed Battour ${ }^{2}$, Kalsom Binti Ali ${ }^{1}$, and Mohammad Nashief ${ }^{1}$ \\ ${ }^{1}$ Faculty of Faculty of Leadership and Management, Universiti Sains Islam Malaysia (USIM), \\ Malaysia. \\ ${ }^{2}$ University of Sharjah, Sharjah, UAE.
}

\begin{abstract}
Manufacturing companies face different challenges due to the continuous and rapid global changes and development in business. Manufacturing companies should review the adopted system and the applied strategies. Therefore, an efficient human capital is needed to survive and to achieve the strategic goals. The human capital management should be able to propose new methods to improve strategic agility under the environment that is rapidly changing, facing severe competition, capable to utilize resources, and following the market trends. Moreover, the human capital management should identify the right competitors, consumers, opportunities, and threats that enable Manufacturing companies to be efficient, rapid, flexible, and proactive. In turn, manufacturing companies' competitive capabilities will be improved; the existing products will stay longer in the market, new products will be introduced, sustainable competitive advantage will be gained, and strategic sovereignty will be achieved in local and regional markets. Thus, this paper discusses the relationship between human resources management (HRM) strategies and sustainable competitive advantage (SCA) where strategic agility is mediating variable. it provides some original insights into the interactions between these variables. This paper is also expected to provide some suggestions to manufacturing companies to success and to survive, especially in Yemen.
\end{abstract}

\section{Introduction}

The world is changing at a rapid pace, driven by science and technology which has led to companies operating in a highly competitive environment (Sheel et al., 2012). This requires industries, especially in developing countries, to adopt a new system or mechanism that is compatible with the requirements of this rapid change. Efficient human capital can recognize the current reality and formulate proactive strategies to cope with the challenges, exploit opportunities, and control threats is essential towards achieving sustainable competitiveness advantage (Alwehabie, 2017; Pfeffer, 1994).

\footnotetext{
* Corresponding author: magedbarahma@gmail.com
} 
Yemeni manufacturing companies like other companies in the developed counties face several challenges such as highly competitive environment comprising the established companies and new companies penetrating the Yemeni market. Yemeni manufacturing companies face serious challenges related to their ability to market the products across the regional market (National Information Centre, 2011). In addition, this situation necessitates companies to reconsider the organizational structures, processes, and the aspects of practical life that include and support the creation of values to develop the capabilities, skills, and knowledge of their employees to put them within their environmental circle, meet their current and future aspirations, and enhance their strategic sovereignty over the Yemeni market due to the role played by the Yemeni manufacturing industry in the country's economy (Qaid, 2010).

Manufacturing sector is important in terms of its significant contribution towards the gross domestic product (GDP) from 2009 until 2015 i.e., 4642156, 5510673, 5331549, 5365742, 5780028, 5485921, and 4102274 million riyals respectively Besides, this sector employs about 118,591 workers; an evidence of its vital role in Yemen (Annual Report, 2015; Yemeni Ministry of Industry and Trade, 2017). This sector has interrelationship with various business fields; hence a competent authority is needed to solve the problems and create the opportunities related to the sector. Among the efforts includes conducting many studies to help the industry deals with the available issues to improve its status in the highly competition environment.

A few researchers have offered suggestions for firms in the context of intense competition and current risks such as the theory of resource - based view (Barney, 1991) and the theory of dynamic capabilities (Teece et al., 1997). These theories focus on resources and skills to build dynamic capabilities in a systematic way that enhance the ability of companies to perceive opportunities and control threats in a pattern that makes it difficult for competitors to emulate it in the market (Li and Liu, 2012). Meanwhile, Tseng and Lin (2011) and Bessant et al. (2000) explained that companies will benefit from this approach to face the challenging business environment.

Competency-based theory, according to some scholars, emphasizes the importance of organizational resources and capabilities in creating value and establishing competitive advantage and sustainability for businesses (Freiling, 2004; Freiling et al., 2008). Furthermore, one of the capabilities that strategic agility includes is a company's ability to make changes, its adaptability, responsiveness, and good performance in a sophisticated and rapidly changing environment (Sambamurthy et al., 2003; Weill et al., 2002).

Furthermore, Appelbaum, Calla, Desautels, and Hasan (2017a) showed that strategic agility is a critical factor contributing to improve organizational performance, sustainable competitive advantage, and survival under the highly competitive environment. At the same time, Tarafdar and Qrunfleh (2017) showed that strategic agility is often referred as critical efficiency that can improve performance and fulfil sustainable competitive advantage. This was also reported by Macclever, Annan, and Boahen (2017) who mentioned that strategic agility positively affects the performance of manufacturing companies as it leads to achieving sustainable competitive advantage by placing them in synchronization frame with their surroundings.

Lewis, Andriopoulos, and Smith (2014) analyzed that many manufacturing companies have adopted modern philosophies and management practices to achieve strategic agility. Introducing the concepts and philosophies of HRM and its strategies is a crucial factor for enhancing the strategic agility for manufacturing companies (Shafer, Dyer, Kilty, Amos, and Ericksen, 2001). This is useful in identifying the necessary steps or mechanisms that the management can use in adapting with the modern changes and development. Further, Strategic agility's previous literature didn't investigate the effect of strategic agility on the 
relationship between human resource management strategies and sustainable competitive advantage.

Based on the discussions, some of the questions that remain are (i) "How can decision makers in manufacturing companies realize the role of HRM strategies and implement them deliberately to attract qualified human resources?" (ii) "How is it possible to develop and acquire skills and abilities to enable the companies to understand the environmental changes?" and (iii) "How to identify or adapt any mechanisms to face the environmental changes, invest in opportunities, and control the threats for the companies to be competitive in the long term?"

Accordingly, there is no evidence of study showing that strategic agility can play a mediating role in enhancing the relationship of HRM strategies and sustainable competitive advantage. Therefore, this paper aims to review the importance of the relationship as an interactive approach to be adopted by Yemeni manufacturing companies. This will help them deal with the existing data, improve their reality, and continue operating considering the mysterious working environment that includes highly competition situation at the local and international regions.

\section{Literature Review}

\subsection{The impact of HRM Strategies on SCA}

There have been a number of analytical studies that attempted to answer two basic questions (i) "Do HRM strategies have a positive impact on achieving sustainable competitive advantage?" and (ii) If so, how can be that effect achieved?" when discussing the correlation and impact relationship between HRM strategies and other variables related to performance, and the correlation and impact relationship between these strategies and SCA, Alwehabie (2017) evaluated the positive impact of HRM strategies including human resources planning strategy, human resources recruitment strategy, human resources training strategy, and human resources performance strategy on corporate performance presented in market share, profitability, general satisfaction, and the degree of supporting leadership to Al Rajhi Bank in Saudi Arabia. The results highlighted the prominent role of these strategies in developing the bank's competitive capability, enhancing its market share, and achieving competitive leadership at the local and regional levels.

Ramadan (2012) also highlighted the impact of talent management represented by the following dimensions i.e., human resources, organisational resources, and financial resources on the competitive advantage of small- and medium-sized enterprises (SMEs) in CANADA. It was shown that good human resource management is significantly linked to productivity and this, in turn, reinforces the premise that human resources is a vital source of achieving SCA. In the same context of the direct relationship between HRM management strategies and competitive advantage, Collins and Clark (2003) studied the impacts of HRM practices on organisational performance competitive advantage. The study was conducted among 73 high-tech companies. Similarly, Lawler (2008) concluded that HRM strategies influence competitive advantage through managing, directing, and motivating employees in an efficient manner in any organisations. 
Moreover, Pahuja and Dalal (2012) posited that HRM practices containing the system of equitable reward, effective communication, employee participation and empowerment, appropriate organisational climate, and training and development are the critical factors in achieving competitive advantage at the State Bank in India.

Jerby (2013) emphasised on the usefulness of HRM strategies dimensions i.e., functional analysis, human resources planning, human resources attraction, training and development, career planning, and human resources performance assessment to achieve sustainable competitiveness advantage. These are all the sources of value creation and help to strengthen the employee motivation, capabilities, skills, and their loyalty to organisations. Although previous studies have proven that HRM strategies are impactful towards sustainable competitive advantage, very few studies have examined the relationship between HRM strategies and SCA, the scarcity of such study in the Yemeni environment. This leads to the following hypothesis:

Hypothesis 1: There is a direct, positive relationship between HRM strategies and sustainable competitive advantage in the Yemeni manufacturing industry.

\subsection{The Impact of HRM Strategies on Strategic Agility}

Despite the importance of the relationship between HRM strategies and strategic agility, there are not many studies that have addressed this relationship. Crocitto and Youssef (2003) focused on the role of human resources in strategic agility through efficient leadership in decision making, reward system, effective training in change management, manager involvement in enhancing strategic role, and formulation of strategy that make organisations more agile. Similarly, Dyer, and Ericksen (2006) explained that HRM strategies contribute to the direction and modification of employee behaviour to continuously develop business requirement, innovation, business model, and solutions to align the organisational internal process with strategic agility features to meet the challenges ahead.

In fact, a number of factors including strategy, infrastructure, staff capabilities, skills, and leadership influence and enhance strategic agility in different ways (Appelbaum et al., 2017a; Appelbaum, Calla, Desautels, and Hasan, 2017b). Baskarada and Koronios (2018) noted that these factors interact with the dynamic capabilities of strategic agility e.g., sensing, searching, seizing, switching, and shaping in order to boost the ability of an organisation to be more proactive in adapting with its reality to capture opportunities and control threats. Likewise, Saha, Gregar, and Sáha (2017) showed that both strategic learning and HRM strategies contribute to enhancing strategic agility and improving organisational performance.

Furthermore, Shafer et al. (2001) highlighted that the five core initiatives representing resource management strategies i.e., selection, recruitment, training and development, performance management, promotion, and compensation are central to enhancing a company's strategic agility. In the same context, according to Bouaziz and Hachicha (2018), human resource training and development strategy and human resource compensation strategy have a greater impact on the promotion of strategic agility than human resource strategy, recruiting strategy, and participation strategy. They called for further studies to analyse the impacts of these strategies in different research contexts. Additionally, Barahma, et al. (2019) indicated that there is a direct impact of human resources management strategies on strategic agility in the large- and medium-sized manufacturing companies operating in Yemen. Based on the discussions, it is clear there are very few numbers of studies that have examined the impact of HRM strategies on strategic agility. This leads to the following hypothesis: 
Hypothesis 2: There is a direct, positive relationship between HRM strategies and strategic agility in the Yemeni manufacturing industry.

\subsection{The Direct Relationship between Strategic Agility and Sustainable Competitive Advantage}

Studying the relationship between strategic agility and sustainable competitive advantage is a core issues that should receive considerable attention among researchers in facing a highly competitive and mysterious work environment. There is, however, a lack of studies on that relationship. Almahamid, Awwad, and McAdams (2010) emphasised on the positive role of strategic agility and knowledge exchange on achieving competitive advantage in Jordanian industrial companies. Additionally, Chen (2012) aimed at understanding the effect of business intelligence and the flexibility of IT infrastructure on competitive advantage through strategic agility as mediating variable. It was revealed that there is an indirect effect of independent variables on the dependent variable "competitive advantage" through "agility" as the mediating variable. Hence, Chen (2012) recommended future studies to analyse the impacts of other independent variables in achieving sustainable competitive advantage using "strategic agility" as the mediating variable especially in a highly competitive business environment.

Furthermore, according to Debiri and Gholami (2015), strategic agility (differentiation in innovation and market differentiation) and competitive advantage are inextricably linked (price, quality, reliability, delivery, and product innovation). It was discovered that strategic agility has a greater impact on differentiation in innovation than market differentiation in achieving competitive advantage. Besides, Hemmati, Feiz, Jalilvand, and Kholghi (2016) showed a significant relationship between company's resources and competitive advantage, company's resources and strategic agility, and agility and competitive advantage.

In the same regard, five dynamic capabilities of strategic agility i.e., sensing, searching, seizing, switching, and formulating specified that strategic agility is central in its role for acquiring sustainable competitive advantage (Baskarada and Koronios, 2018, Bhatti, Kaur, \& Battour, 2013, Zainab, Bhatti, Pangil, \& Battour, 2015, Battour et al.,2021). Thus, based on the discussions, it is clear there is a scarcity in the studies investigating the effective relationship of strategic agility on sustainable competitive advantage especially in the context of Yemen. This leads to the following hypothesis:

Hypothesis 3: There is a direct, positive relationship between strategic agility and sustainable competitive advantage in the Yemeni manufacturing industry.

\subsection{The Indirect Relationship between HRM Strategies and Sustainable Competitive Advantage through Strategic Agility as the Mediating Variable}

According to the best knowledge of the researcher, thus far, there is no conceptual or empirical conducted on the indirect relationship between HRM strategies and sustainable competitive advantage through strategic agility as the mediating variable. Baron and Kenny (1986) suggested that the use of mediating variables require some conditions to be met which are related to proving a relationship with statistical significance between the independent variable and the dependent variable, as well as proving the existence of a statistically significant relationship between the independent variable and the mediating variable.

In this regard, the fourth hypothesis is proposed according to the interaction between the theories of resource - based view and dynamic capabilities. HRM strategies is an organisational resource that focuses on reorienting employee behaviour in a way that enhances their abilities and skills in understanding the strategic reality. Strategic 
approaches that necessitate the building of multiple business models require the restructuring of the company's internal capabilities in developing existing products and creating new products. This can avoid product imitation from other competitors, hence achieving competitive advantage and eventually lead to a company being able to acquire strategic sovereignty over market.

Hypothesis 4: There is an indirect, positive relationship between HRM strategies and sustainable competitive advantage through strategic agility as the mediating variable in Yemen.

Based on the extant literature and empirical studies, a conceptual framework was developed for this study that illustrates the relationship of the variables (see figure 1).

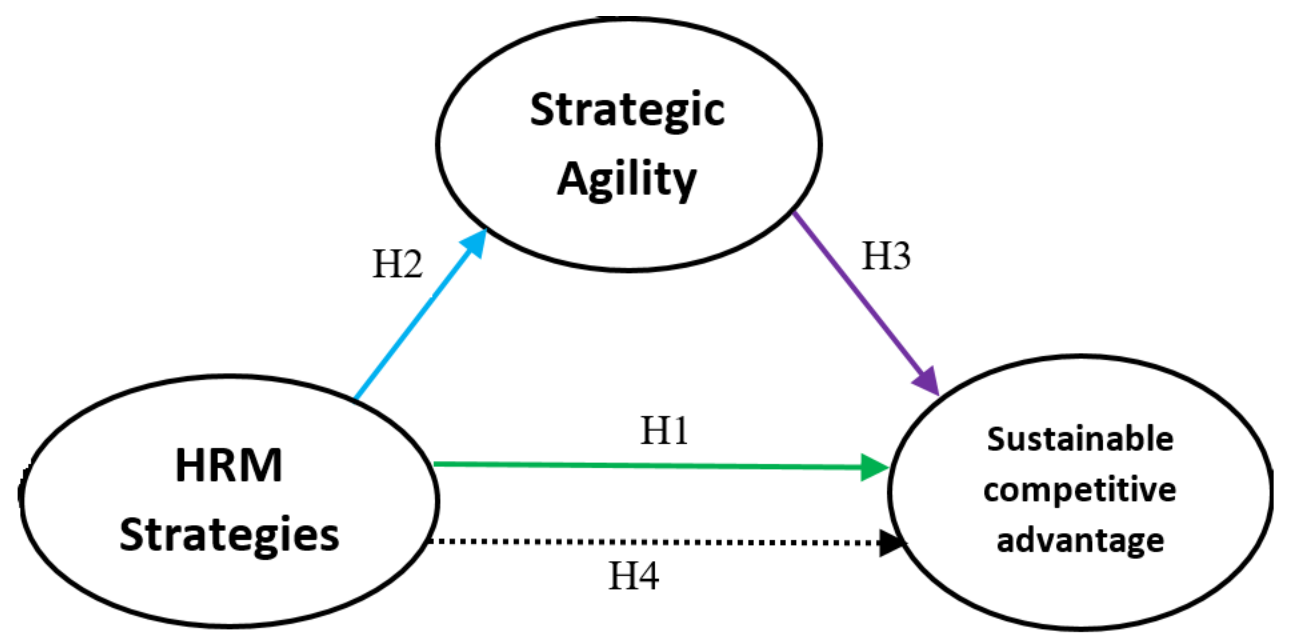

Fig. 1: The proposed conceptual framework to predict the relationship between HRM strategies, strategic agility, and sustainable competitive advantage.

\section{Conclusion}

HRM strategies have been adopted in many organizations as a core resource that enhances organization's ability to acquire human competencies, develop their abilities and skills, and strengthen their loyalty towards work to do more and fulfil their assigned duties as planned. HRM strategies also strengthen the knowledge needed to understand a company's strategic reality in formulating optimal proactive strategic approaches for building multiple business models that require restructuring the company's internal capabilities, to be consistent with the dynamics of the environment, to re-emerge from the inside simultaneously, to exploit opportunities, to control threats, to meet the renewed needs of customers, to face the competitors, to achieve sustainable competitive advantage, to prevent the imitation of the company's features, and to retain the company's strategic sovereignty over market.

For example, in the case of Nokia, although the giant mobile device manufacturer achieved high profit in the beginning, however, the success did not last for a long period of time because it did not focus on developing the employee skills and capabilities to face the dynamic environment and intense competition in the market. This has contributed to the loss of a large part of its market share and its inability to meet the renewed needs of customers to confront high-tech competitors in the framework of mobile phones. In the reviews of literature, previous studies have shown that direct HRM strategies particularly 
have significant impacts in terms of achieving and enhancing strategic agility and sustainable competitive advantage.

Not only the studies about the role of direct HRM strategies in strategic agility and the role of direct strategic agility in sustainable competitive advantage are limited, most of these studies also generally focused on the role of agility in achieving competitive advantage. Hence, according to the best knowledge of the researcher, thus far, there is no empirical study that deals with the direct relationship between these variables in Yemen. There is also no conceptual or empirical study attempting to reveal the indirect relationship between HRM strategies and sustainable competitive advantage through strategic agility at the external and local levels. Consequently, this study revealed the interactive relationship between these variables, thus enriching the body of knowledge about such findings in order to study them experimentally in various research contexts.

Therefore, manufacturing companies in general, and Yemeni manufacturing companies in particular, should pay more attention to HRM strategies and strategic agility and how to apply these two concepts in a scientific manner in order to achieve SCA. This is important in overcoming the current and future problems resulting from the rapid changes in a highly competitive market.

\section{References}

Almada, L., \& Borges, R. (2018). Sustainable Competitive Advantage Needs Green Human Resource Practices: A Framework for Environmental Management. Revista de Administração Contemporânea, 22(3), 424-442.

Almahamid, S., Awwad, A., \& McAdams, A. C. (2010). Effects of organizational agility and knowledge sharing on competitive advantage: an empirical study in Jordan. International Journal of Management, 27(3), 387.

Alwehabie, A. M. (2017). Criteria for Measuring the Efficiency and Effectiveness of Human Resources Management Strategy and its Relation to Institutional Performance at Al Rajhi Bank at Al Qassim in Saudi Arabia from the Employees' Point of View. International Journal of Business and Management, 12(10), 111.

Appelbaum, S. H., Calla, R., Desautels, D. \& Hasan, L. (2017a). The challenges of organizational agility (part 1). Industrial and Commercial Training, 49(1), 6-14.

Appelbaum, S. H., Calla, R., Desautels, D., \& Hasan, L. N. (2017b). " The challenges of organizational agility: part 2 ", Industrial and Commercial Training, Vol. 49 Iss 2 pp. 69 - 74 Permanent link to this document: http://dx.doi.org/10.1108/ICT-05-2016-0028

Armstrong, M., \& Brown, D. (2019). Strategic Human Resource Management: Back to the future?

Battour, M., Barahma, M., \& Al-Awlaqi, M. (2021). The Relationship between HRM Strategies and Sustainable Competitive Advantage: Testing the Mediating Role of Strategic Agility. Sustainability, 13(9), 5315.

Barney, J. (1991). Firm resources and sustained competitive advantage. Journal of Management, 17(1), 99-120.

Bhatti, M. A., Kaur, S., \& Battour, M. M. (2013). Training transfer and transfer motivation in the Malaysian banking sector. Global Business and Organizational Excellence, 33(1), 40-57.

Baron, R. M., \& Kenny, D. A. (1986). The moderator-mediator variable distinction in social psychological research: Conceptual, strategic, and statistical onsiderations. Journal of personality and social psychology, 51(6), 1173.

Baskarada, S., \& Koronios, A. (2018). The 5S organizational agility framework: a dynamic capabilities perspective. International Journal of Organizational Analysis. 
Barahma, M. M., ALi, K. B., Nashief, M., \& Al-Awlaqi, M. A. (2019). The Impact OF Human Resources Management Strategies on the Strategic Agility: A Field Study in large and medium Yemeni manufacturing Sector. Journal of Social Sciences (COES\&RJ-JSS), 8(4), 611-629.

Bessant, J., Francis, D., Meredith, S., Kaplinsky, R., \& Brown, S. (2000). Developing manufacturing agility in SMEs. International Journal of Manufacturing Technology and Management, 2(1-7), 730-756.

Bouaziz, F., \& Smaoui Hachicha, Z. (2018). Strategic human resource management practices and organizational resilience. Journal of Management Development. doi :https://doi.org/10.1108/ JMD-11-2017-0358

Chen, X. (2012). Impact of business intelligence and IT infrastructure flexibility on competitive advantage: An organizational agility perspective.

Collins, C. J., \& Clark, K. D. (2003). Strategic human resource practices, top management team social networks, and firm performance: The role of human resource practices in creating organizational competitive advantage. Academy of Management Journal, 46(6), 740-751.

Crocitto, M., \& Youssef, M. (2003). The human side of organizational agility. Industrial Management \& Data Systems, 103(6), 388-397.

Dabiri, S. A \& Gholami, A. (2015). Surveying the effect of strategic agility on gaining competitive advantage in Gachsaran Oil and Gas Exploitation Company, Journal of Renewable Natural Resources Bhutan

Dyer, L., \& Ericksen, J. (2006). Dynamic organizations: Achieving marketplace agility through workforce scalability. Cornell University 187 Ives Hall Ithaca, NY 148533901

Dyer, L., \& Shafer, R. A. (1998). From human resource strategy to organizational effectiveness: Lessons from research on organizational agility.

Freiling, J. (2004). A Competence-based Theory of the Firm. management revue, 27-52.

Freiling, J., Gersch, M., \& Goeke, C. (2008). On the path towards a competence-based theory of the firm. Organization Studies, 29(8-9), 1143-1164.

Hemmati, M., Feiz, D., Jalilvand, M. R., \& Kholghi, I. (2016). Development of fuzzy twostage DEA model for competitive advantage based on RBV and strategic agility as a dynamic capability. Journal of Modelling in Management, 11(1), 288-308. https://doi.org/10.1108/JM2-12-2013-0067

Lawler, E. E. (2008). Make human capital a source of competitive advantage. Marshall School of Business Working Paper No. MOR, 16-09.

Lee, C. C., Strohl, K., Fortenberry, M., \& Cho, C. Y. S. (2017). Impacts of Human Resources Management Innovations on Productivity and Effectiveness in A MediumSize Non-Profit Organization. Global Journal of Management and Marketing, 1(1), 51.

Lewis, M. W., Andriopoulos, C., \& Smith, W. K. (2014). Paradoxical leadership to enable strategic agility. California Management Review, 56(3), 58-77.

Li, D. Y., \& Liu, J. (2012). Dynamic capabilities, environmental dynamism, and competitive advantage: Evidence from China. Journal of Business Research, 67(1), 2793-2799.

Macclever, A. B., Annan, J., \& Boahen, S. (2017). Supply Chain Flexibility, Agility and Firm Performance.

National center for information, Information material on the industrial sector in the Republic of Yemen (2011).

Pahuja, S., \& Dalal, R. C. (2012). Achieving Competitive Advantage through HR Practices: A Case Study. Journal of Strategic Human Resource Management, 1(2), 35. 
Pfeffer, J. (1994). Competitive advantage through people. California management review, 36(2), 9-28.

Potdar, P. K., Routroy, S., \& Behera, A. (2017). A benchmarking approach for enhancing agility in manufacturing environment. International Journal of Productivity and Quality Management, 20(4), 488-512.

Qaid, Ali Abdullah. (2010). The large and medium industries sector in the Republic of Yemen, the fourth Arab forum entitled quality and creativity with the existence of globalization (25-26) Sana'a.

Zainab, B., Bhatti, M. A., Pangil, F. B., \& Battour, M. M. (2015). E-training adoption in the Nigerian civil service. European Journal of Training and Development. 